\title{
Change in the Circulation Regime in the Stratified Saline Lake Shira (Siberia, Republic of Khakassia)
}

\author{
V. M. Belolipetskii ${ }^{a}$, A. G. Degermendzhi ${ }^{b}$, S. N. Genova ${ }^{a}$, and D. Y. Rogozin ${ }^{a, c *}$ \\ Received June 20, 2016
}

\begin{abstract}
The in-situ data on the vertical structure and stability of the vertical stratification of saline Lake Shira over the past decade (2007-2015) are analyzed. Simplified mathematical models have shown that strong wind in the autumn of 2014 together with rather thick ice in the winter of 2015 caused a change in the circulation regime of this water reservoir from meromictic (incomplete mixing) to holomictic (compete mixing). Based on the results obtained, a circulation regime for deep saline lakes located in the continental climate zone, in particular, in the arid zones of Southern Siberia (Khakassia, Transbaikal, and Altai) can be predicted under various climate scenarios of the future.
\end{abstract}

DOI: $10.1134 / \mathrm{S} 1028334 \mathrm{X} 17060010$

A water reservoir is called meromictic if during the course of a year seasonal circulation of its water stratum involves only the upper part of the water stratum (the so-called mixolimnion). The deep waters in a meromictic state (monimolimnion) do not participate in seasonal circulation; therefore, biogenic elements incoming together with the flow of settling organics become inaccessible to the main producers and aerobic phototrophic microorganisms are withdrawn from biotic circulation. Thus, biogenic elements accumulate in a monimolimnion. It has been shown several times that during meromixis disturbance, i.e., in complete mixing (holomixis), biogenes are released from the monimolimnion, which leads to outbursts of phytoplankton biomass, i.e., to worsening of water quality and changes in the species composition of plankton organisms [1]. Therefore, the prediction for transitions of the states of a lake from meromictic to holomictic and vice versa is urgent from the viewpoint of prediction of water quality under conditions of global climate changes.

Lake Shira is one of the most studied small lakes in Siberia. Data on its ecosystem have been published in many sources [2]. This lake is an important recreation and balneological object. The well-known resort "Lake Shira" is situated on its coast. Therefore, it is especially urgent to predict its water quality. Before

\footnotetext{
${ }^{a}$ Institute of Computational Modeling, Siberian Branch, Russian Academy of Sciences, Krasnoyarsk, Russia

${ }^{b}$ Institute of Biophysics, Siberian Branch, Russian Academy of Sciences, Krasnoyarsk, Russia

${ }^{c}$ Siberian Federal University, Krasnoyarsk, Russia

*e-mail: rogozin@ibp.ru
}

2013 inclusive, Lake Shira remained a meromictic water reservoir [3]; however, in the subglacial period of 2014-2015, we recorded mixing of the water stratum to the bottom, which was accompanied by the disappearance of hydrogen sulfide from the deep layers of the lake.

In this work, we analyzed the in-situ data on the vertical structure of Lake Shira over the recent period (2007-2015) and, using simplified mathematical models, we showed that a strong wind action in the autumn of 2014 together with quite thick ice in the winter of 2015 caused a change in the circulation regime of this water reservoir from meromictic (incomplete mixing) to holomictic (compete mixing). This result confirms the possibility of predicting the depth of seasonal mixing in saline water reservoirs of the moderate zone based on simple mathematical models.

The intensity of water mass mixing depends on the vertical density gradient. In turn, the density is determined by the temperature and salinity. Based on the data of long-term monitoring, earlier we described a seasonal dynamic of vertical distributions of these characteristics in the saline meromictic lake [4]. When ice cover is absent, the water stratum of the stratified lake is mixed by vertical turbulent exchange and wind currents. In the winter, when ice is formed in saline lakes, salt is released as a result of crystallization. The unstable density stratification formed leads to intense vertical circulation and formation of a convective mixed layer. Convective mixing spreads to the height where the water density becomes equal to the density of the underlying water layer. In this case, the temperature and salinity are equalized $[5,6]$. In the spring and summer, when the upper water layer is heated, the 
Table 1. Characteristics of vertical distributions of salinity in Lake Shira in the autumn before ice formation and the estimated critical values of the wind speed. The designations are the same as in Fig. 1 and formula (1)

\begin{tabular}{l|c|c|c|l|l|l}
\hline $\begin{array}{c}\text { Date of } \\
\text { measurements }\end{array}$ & $\begin{array}{c}d_{1}, \\
\mathrm{~m}\end{array}$ & $\begin{array}{c}d_{2}, \\
\mathrm{~m}\end{array}$ & $\begin{array}{c}d_{3}, \\
\mathrm{~m}\end{array}$ & $\begin{array}{l}S_{0}, \\
\mathrm{~g} / \mathrm{l}\end{array}$ & $\begin{array}{l}S_{b t}, \\
\mathrm{~g} / 1\end{array}$ & $\begin{array}{l}W_{\bullet}, \\
\mathrm{m} / \mathrm{s}\end{array}$ \\
\hline Oct. 27, 2007 & 14.06 & 4.24 & 5.1 & 15.25 & 17.98 & 20.5 \\
Oct. 28, 2008 & 11.06 & 8.34 & 4.6 & 15.71 & 17.5 & 17.5 \\
Oct. 20, 2009 & 9.8 & 6.27 & 7.93 & 15.6 & 17.6 & 19.2 \\
Oct. 24, 2012 & 12.8 & 1.8 & 9.6 & 16.65 & 18.88 & 20.2 \\
Oct. 23, 2013 & 12.27 & 7.07 & 4.81 & 17.0 & 19.2 & 19.2 \\
\hline
\end{tabular}

density stratification intensifies. In the autumn, the water reservoir cools down; before the formation of ice, the water temperature changes little with depth and the density stratification is mainly determined by the salinity gradient. In this period, the stability of the lake against mixing becomes the lowest.

To evaluate the dynamics of the vertical structure of the stratified water reservoir, we consider the following simplified statement of the problem. A stratified water reservoir is schematized by a three-layer fluid (Fig. 1). In the upper water layer that adjoins the free surface, the water density has a constant value due to mixing (epilimnion); in a pycnocline, the density changes linearly with depth (metalimnion); in the bottom layer, the density changes little, $\rho \approx$ const (hypolimnion), $d_{1}, d_{2}, d_{3}$ are thicknesses of the respective layers, $d_{1}+d_{2}+d_{3}=H$ is the depth of the water reservoir. Before the formation of ice, we consider a vertical distribution of salinity in the form

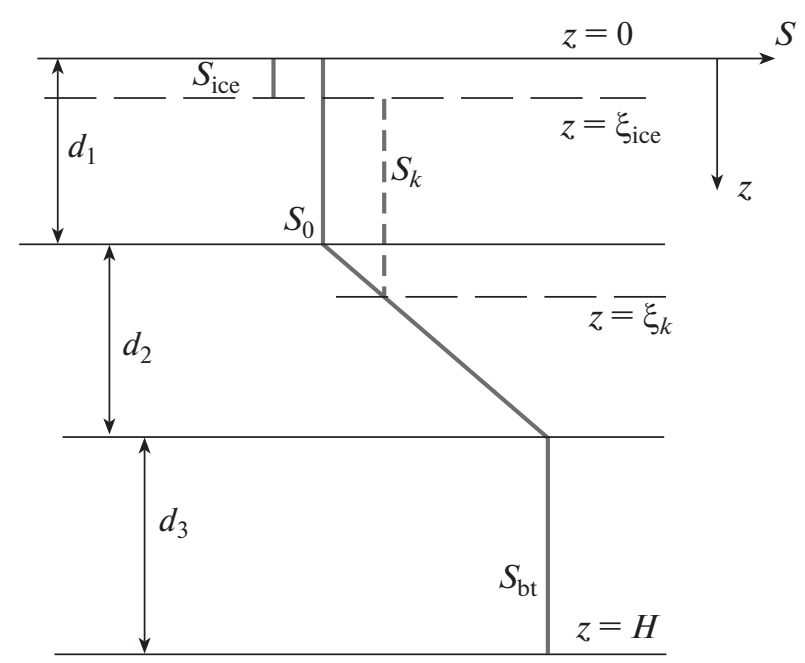

Fig. 1. Three-layer model of vertical distribution of salinity in a stratified lake.

$$
=\left\{\begin{array}{l}
\quad S(z) \\
S_{0}, \quad 0 \leq z \leq d_{1}, \\
S_{0}+\left(S_{b t}-S_{0}\right) \frac{z-d_{1}}{d_{2}}, \quad d_{1} \leq z \leq d_{1}+d_{2}, \\
S_{b t}, \quad d_{1}+d_{2} \leq z \leq H .
\end{array}\right.
$$

to be known.

Here, $S_{0}=$ const is the water salinity of the upper layer, $S_{b t}=$ const is the salinity of the near-bottom layer, $H$ is the lake depth, $d_{1}$ is the depth of the upper layer, and $d_{2}$ is the thickness of the central layer. Let the thickness of the ice cover $\xi_{\text {ice }}$ be known $\left(\xi_{\text {ice }}<d_{1}\right)$. Since in cold seasons, the vertical temperature changes little, the main contribution to the density gradient is made by salinity. The thickness of the convective mixed layer $\left(\xi_{k}-\xi_{\text {ice }}\right)$ is determined from the condition of salt concentration equality in the layer of convective mixing $S_{k}$ and water salinity at the depth $\xi_{k}$. We obtain an expression from the balance condition for estimation of the depth of the convective mixed layer under the ice cover:

$$
\xi_{k}=\xi_{\text {ice }}+\sqrt{\xi_{\text {ice }}^{2}+2 d_{2} \xi_{\text {ice }} \frac{S_{0}-S_{\text {ice }}}{S_{b t}-S_{0}}+d_{1}\left(d_{1}-2 \xi_{\text {ice }}\right)}
$$

Thus, in the winter, the thickness of the convective mixed layer depends on the values of $S_{0}, S_{b t}, d_{1}, d_{2}$ in the autumn (before ice formation) and on $\xi_{\text {ice }}, S_{\text {ice }}$.

It is evident that at $\xi_{k}>d_{1}+d_{2}$ the layer of convective mixing spreads to the bottom. Thus, we determine the ice thickness $\xi_{m}$ from relation (2); when it is exceeded, the layer of convective mixing will spread to the bottom:

$$
\xi_{m}=\frac{\left(d_{1}+0.5 d_{2}\right)}{\left[1+\left(S_{0}-S_{\text {ice }}\right) /\left(S_{b t}-S_{0}\right)\right]} .
$$

For the qualitative evaluation of mixing regimes in saline lakes in the periods of absence of ice cover, we use a two-layer fluid model [7] (Fig. 2). When the wind is weak, two circulation zones are formed in the vertical plane, the upper water layers are not mixed with the bottom ones (Fig. 2a). When the wind is quite strong $W>W_{\bullet}$, one circulation zone is formed, and the near-bottom layers are mixed with the surface layers (Fig. 2b). According to the hypothesis on spreading of water stratum mixing to the bottom, if the typical water flow velocity in the upper layer exceeds the velocity of internal wave propagation, we obtained a formula for calculation of the critical wind speed $W$. [7]:

$$
W_{\bullet}=\frac{c}{1.932} \times 10^{2}, c=\sqrt{\frac{g \Delta \rho}{\rho_{0}} \frac{h_{1} h_{2}}{h_{1}+h_{2}}},
$$


Table 2. Measured and estimated characteristics of the ice thickness and the depth of the convective mixed layer in Lake Shira. The designations are the same as in formulas (2) and (3)

\begin{tabular}{l|l|l|c|c}
\hline \multicolumn{1}{c|}{ Date } & $\xi_{\text {ice }}, \mathrm{m}$ & $\xi_{m}, \mathrm{~m}$ & $\begin{array}{c}\xi_{k}, \mathrm{~m} \\
\text { estimated }\end{array}$ & $\begin{array}{c}\xi_{k}^{n}, \mathrm{~m} \\
\text { measured }\end{array}$ \\
\hline Mar. 22, 2008 & 0.9 & 2.87 & 15.28 & 15.76 \\
Mar. 12, 2009 & 1.02 & 1.83 & 16.03 & 16.0 \\
Mar. 31, 2010 & 1.3 & 1.59 & 16.43 & 17.6 \\
Mar. 19, 2011 & 1.04 & 1.61 & 11.04 & 12.4 \\
Mar. 4, 2012 & 0.5 & 2.03 & 9.73 & 11.6 \\
Mar. 15, 2013 & 1.01 & 1.9 & 13.73 & 14.9 \\
Mar. 13, 2014 & 0.88 & 1.98 & 15.4 & 18.0 \\
\hline
\end{tabular}

where $h_{1}=d_{1}+0.5 d_{2}, h_{2}=d_{3}+0.5 d_{2}, h_{1}, h_{2}$ are the thicknesses of the upper and lower layer, respectively (for the two-layer scheme).

Based on the salinity profiles measured in Lake Shira in the autumn, we estimated the critical wind speeds $W$. before ice formation from formula (4) (Table 1).

Over these years, the lake was meromictic; i.e., the total mixing did not spread to the bottom, and the depths $\xi_{k}$ of the convective layer in the winter determined from formula (2) are consistent with the measured values of $\xi_{k}^{n}$ (Table 2). The maximum ice thickness that causes mixing to spread to the bottom and that is calculated by formula (3) is also significantly greater than the values observed over these years. It is seen that for the periods of the lake meromictic state
Table 3. Estimated and measured characteristics of the autumn salinity profiles in Lake Shira and estimated critical values of wind velocity

\begin{tabular}{l|c|c|c|c|c|c}
\hline \multicolumn{1}{c|}{ Date } & $\begin{array}{c}d_{1}, \\
\mathrm{~m}\end{array}$ & $\begin{array}{c}d_{2}, \\
\mathrm{~m}\end{array}$ & $\begin{array}{c}d_{3}, \\
\mathrm{~m}\end{array}$ & $\begin{array}{c}S_{0}, \\
\mathrm{~g} / 1\end{array}$ & $\begin{array}{c}S_{b t}, \\
\mathrm{~g} / 1\end{array}$ & $\begin{array}{l}W_{\bullet}, \\
\mathrm{m} / \mathrm{s}\end{array}$ \\
\hline $\begin{array}{l}\text { Oct. 28, 2008, } \\
\text { in-situ }\end{array}$ & 11.06 & 8.34 & 4.6 & 15.7 & 17.5 & 17.5 \\
$\begin{array}{l}\text { Jul. 24, 2008-Oct. } \\
\text { 8, 2008, estimation } \\
\begin{array}{l}\text { Oct. 23, 2013, } \\
\text { in-situ }\end{array}\end{array}$ & 8.41 & 20.8 & 3.46 & 15.3 & 17.3 & 18.8 \\
$\begin{array}{l}\text { Jul. 8, 2013-Oct. } \\
\text { 23, 2013, estimation }\end{array}$ & 10.09 & 9.89 & 3.46 & 16.54 & 18.91 & 20.0 \\
\hline
\end{tabular}

considered, the estimated critical wind speed exceeded $17.5 \mathrm{~m} / \mathrm{s}$.

We proceed to the year 2014. Unfortunately, no measurements were performed in Lake Shira in the autumn of 2014. Therefore, to estimate the value of critical wind speed, we use the calculations of vertical distributions of the water temperature and salinity by the model that we earlier developed and that is based on solving one-dimensional vertical diffusion equations for temperature and salinity [5]. The adequacy of this model was confirmed by the satisfactory coincidence between the estimated distributions and the insitu data [4].

For greater reliability, we check this method for the periods with the known measurements in the summer and the autumn. Table 3 presents the results for the calculations of $W$. according to the in-situ data and the data estimated for the periods of July 24, 2008, to

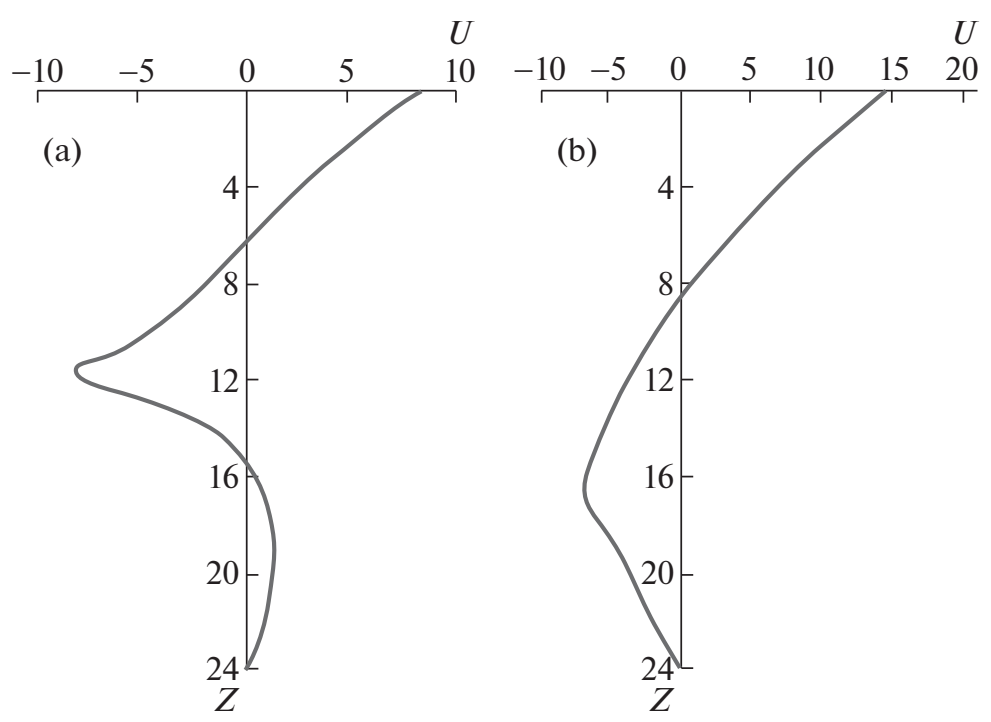

Fig. 2. Vertical profile of the horizontal component of the flow velocity: (a) for a meromictic water reservoir $\left(W<W_{\bullet}\right)$ and (b) when mixing spreads to the bottom $\left(W>W_{\bullet}\right)$. 
October 28, 2008, and July 8, 2013, to October 23, 2013. The differences are insignificant, about $1 \mathrm{~m} / \mathrm{s}$.

We consider the summer and autumn of 2014 from May 28, 2014, to Oct. 25, 2014. The critical wind speed determined by formula (4) using the results of calculations by the $1-\mathrm{D}$ model is $14.1 \mathrm{~m} / \mathrm{s}$, i.e., significantly less than the minimum estimated speed recorded in the previous years. According to the data of the Hydrometeoservice of Russia from Shira radiostation, strong winds of $13-16 \mathrm{~m} / \mathrm{s}$ was recorded on Oct. 12, 2014, Oct. 22, 2014, and Oct. 30, 2014. In the autumns of the other years, the wind speed did not exceed the respective critical value before ice formation. Since the wind speed did not exceed the critical values, the wind mixed the surface layer and the bottom layer, which led to a decrease in $\Delta S=S_{0}-S_{b t}$. The calculations for the 2D model in the vertical plane [7] for the density stratification recorded at a wind speed of $15 \mathrm{~m} / \mathrm{s}$ showed that, as a result of wind mixing, the salinity of the epilimnion $S_{0}$ increased by no more than $0.4 \mathrm{~g} / 1$.

Then, the $\xi_{k}$ value calculated by formula (2) for $\xi_{\text {ice }}=0.92$ will be equal to $23.2 \mathrm{~m}$ (which coincides with the value measured on Mar. 6, 2015); the ice thickness $\xi_{m}$ value will be equal to $0.926 \mathrm{~m}$; when this value is exceeded, the convective mixed layer spreads to the bottom. According to the calculations, the maximum ice thickness in March 2015 was $0.945 \mathrm{~m}$ and the measured value equaled $0.92 \mathrm{~m}$. Therefore, the convective mixed layer spread to the bottom. As a result, the hydrogen sulfide layer disappeared, which we revealed in May 2015. Later, in the summer of 2015, hydrogen sulfide again appeared in the hypolimnion of the lake, which is typical of many stratified lakes in the summer period. However, the hydrogen sulfide concentration was significantly less (the data are not presented).

Thus, we showed that the loss of meromixis of Lake Shira recorded in the winter of 2015 was caused by strong winds in the autumn of 2014 and an ice thickness that exceeded the critical value $\xi_{m}$ in March 2015.

We note that in this work we do not analyze why the salinity gradient before the ice formation and the ice thickness were greater or smaller in the particular year. It is evident that the salinity profile shape depends on the meteorological scenario of the entire previous warm period [4], as well as on the spring start distribu- tion, which, in turn, also depends on the ice thickness in the previous winter and on the value of the spring flood. In addition, a significant role is played by the change in the lake level due to the change in the precipitation-evaporation balance in this area. All these factors can be taken into account in the simulation models, e.g., the ones we proposed earlier [5, 6]. In this work, we analyzed stability of the water stratum in the lake for the assigned autumn profiles of salinity and the values of ice thickness in 2007-2015 and found the reason for the transition of the lake to the holomictic regime. Based on the results obtained, the circulation regime can be predicted for deep saline lakes located in the zone of continental climate, in particular, in the arid zones of Southern Siberia (Khakassia, Transbaikal, and Altai) under different scenarios of the future.

\section{ACKNOWLEDGMENTS}

This work was supported in part by the Russian Foundation for Basic Research (project no. 16-0500091) and in part by the Council for Grants of the President of the Russian Federation for State Support of Leading Scientific Schools (grant NSh-9249.2016.5).

\section{REFERENCES}

1. S. MacIntyre and R. Jellison, Hydrobiologia 466, 1329 (2001).

2. A. G. Degermendzhy, Y. S. Zadereev, D. Y. Rogozin, I. G. Prokopkin, Y. V. Barkhatov, A. P. Tolomeev, E. B. Khromechek, J. P. Janse, W. M. Mooij, and R. D. Gulati, Aquat. Ecol. 44, 619-632 (2010).

3. D. Yu. Rogozin, V. V. Zykov, and M. O. Tarnovskii, Microbiology (Moscow) 85 (1), 93-101 (2016).

4. D. Y. Rogozin, S. N. Genova, R. D. Gulati, and A. G. Degermendzhy, Aquat. Ecol. 44 (3), 485-496 (2010).

5. V. M. Belolipetskii and S. N. Genova, Vychisl. Tekhnol. 13 (4), 34-43 (2008).

6. S. N. Genova, V. M. Belolipetskii, D. Y. Rogozin, A. G. Degermendzhy, and W. M. Mooij, Aquat. Ecol. 44 (3), 571-584 (2010).

7. V. M. Belolipetskii and P. V. Belolipetskii, Prikl. Mekh. Tekh. Fiz. 57 (1), 11-15 (2016).

Translated by L. Mukhortova

\section{SPELL OK}

